\title{
Determinismo e liberdade da vontade: o enfoque biológico
}

\author{
ERASMO GARCIA MENDES
}

$\mathrm{N}$

O FINAL DA DÉCADA de 70, a então Coordenadoria de Assuntos Culturais (Codac) da Reitoria da USP patrocinou uma série de palestras sobre o tema $A$ Liberdade de Vontade na qual a polêmica determinismo versus voluntarismo foi enfocada de vários ângulos por docentes de diferentes setores da Universidade. A série foi coordenada pelo professor Manuel Pedro Pimentel (Faculdade de Direito), na ocasião secretário da Justiça do Estado. O objetivo seria colher subsídios para a reforma do Código Penal. Os resultados da iniciativa, ao que se saiba, nunca foram publicados. Lamentavelmente, pois houve excelentes contribuições da parte de juristas, educadores, sociólogos, filósofos e o determinismo foi tratado inclusive do ponto de vista da Física. Este artigo refere-se à contribuição do autor no enfoque biológico da questão.

Preliminarmente, devo declarar que hesitei bastante antes de aceitar a incumbência de enfocar biologicamente o tema objeto das reuniões referidas. $\mathrm{Na}$ verdade, não insistiram muito em que eu próprio fosse o relator da matéria, aceitaram até que eu, tendo declarado a minha pouca competência no assunto, procurasse, entre os biólogos disponíveis, os que, a meu ver, melhor poderiam dar conta do recado. Pus-me, assim, em contato principalmente com aqueles biólogos que me pareceram atuar nos campos da biologia nos quais indagações sobre o determinismo e a liberdade da vontade pudessem surgir com mais freqüência, a saber, os geneticistas humanos e os etologistas. Houve, porém, da parte dos com quem mantive contato, uma terminante recusa, baseada em motivos que oscilaram entre declarações de incompetência e afirmações de se tratar de discussão bizantina. Recorri até a um eminente vulto da cultura latino-americana, o venezuelano Marcel Roche, editorchefe da revista Interciência, fundamentalmente um biólogo. Respondeu-me o Dr. Roche: "Realmente, Ud. está metido em um verdadeiro atolladero teniendo que hablar sobre Determinismo y Libertad! No lo envidio y tengo muy poco que contribuir al tema...".

Assim, não encontrando quem se dispusesse, tive de recorrer a mim mesmo, um pesquisador que se ocupa dos aspectos moleculares e ecológicos da fisiologia animal, logo, por sua formação, com algum parti pris no assunto a discutir, resultante de sua propensão de abordar algo deterministicamente os problemas, biológicos ou não. Aliás, foi o determinismo que me parece responsável por me ver eu na circunstância de falar sobre o tema em tela. Não tivesse eu me tornado um 
docente universitário e, por decorrência, ter convivido e estar ainda convivendo na Universidade com colegas que atuam em vários campos do saber, e não teria sido procurado para participar destas reuniões. Fui deterministicamente procurado e não tive, ao final, a liberdade de recusar, mesmo porque, a partir do convite, cresceu em mim a curiosidade de me enfronhar num assunto que, no passado, despertara em mim um interesse apenas ocasional.

Ainda uma consideração preliminar final. Refere-se às poucas oportunidades que um pesquisador experimental, dada a natureza do seu trabalho, tem de se ocupar algo filosoficamente com os resultados que consegue, o que condiciona a sua progressiva alienação, a sua limitação a um particular campo de atividade, em detrimento não raro da visão global. É, pouco ou muito, a situação de muitos, certamente, a minha.

Naturalmente, vou me dispensar de me aprofundar na conceituação do determinismo como a teoria de que toda escolha é o resultado determinado ou necessário de causas previamente existentes mentais, físicas ou ambientais e, nesse sentido, oposta ao livre desejo (voluntarismo, libertarianismo, indeterminismo) e mais ou menos aparentada com o necessitarismo ou fatalismo. Gostaria, no entanto, de seguir o critério que distingue dois tipos de determinismo a fim de situar a minha posição quase dentro de um deles. O primeiro tipo considera que cada ação é causalmente conectada não somente com o ambiente do agente, mas também, internamente, com seus motivos e impulsos. Se fosse possível saber exatamente todas essas condições, seria igualmente possível predizer com precisão matemática o curso que o agente poderia seguir. Nesse tipo, o agente não pode de modo algum ser tido como responsável por sua ação. No segundo tipo considera-se que, dentro de certos limites, o indivíduo é livre para fazer sua própria escolha de alternativas e chega-se a admitir que pode haver, em qualquer ação, que não é nem reflexa (no sentido neurológico) nem determinada por causas externas, um elemento de vontade. Esses dois tipos de determinismo são, algumas vezes, distinguidos como duro e mole. A predisposição determinística de que me confessei possuído anteriormente não impede de me considerar como um determinista do tipo mole, ainda que com certas reservas.

A controvérsia entre determinismo e libertarianismo giraria grandemente em torno do significado da palavra motivo. Em nenhuma outra controvérsia filosófica, afirmam os especialistas, tanta dificuldade teria sido causada por uma disputa puramente verbal e ambigüidade de expressão. Quando, e em que sentido, pode uma ação determinada por motivos ser dita livre? A doutrina da evolução teria ido longe no sentido de obliterar a distinção entre compulsão interna e externa, isto é, motivos, caráter e coisas semelhantes. Na medida em que o homem pode ser demonstrado como um produto de (e um elo em) uma longa cadeia de desenvolvimento causal, pode-se tornar impossível considerá-lo inteiramente autodeterminado. Mesmo nos seus motivos e nos seus impulsos, na sua atitude mental para com as circunstâncias exteriores, nos seus apetites e aversões, a tendência herdada e o ambiente poderiam desempenhar um papel muito grande. Isso tem levado muitos 
pensadores a sustentar que todo o desenvolvimento do homem, mental tanto quanto físico, é determinado por condições externas.

Evidentemente, não é só a doutrina da evolução que tem contribuído para que uma atitude favorável ao determinismo se radique e cresça nos pesquisadores das ciências biológicas. $\mathrm{O}$ enorme avanço nos campos da física, da química e de particulares setores do biológico a partir do último quartel do século passado, contribuiu igualmente para incrementar essa atitude. Numa analogia, o determinismo teria se beneficiado desse avanço como, numa outra controvérsia clássica, o mecanismo com relação ao vitalismo. E, ampliando a analogia, pode-se dizer que em ambas as controvérsias o lado menos favorecido pelo progresso das ciências exatas e biológicas continua, não obstante, a ter notáveis adeptos que defendem suas posições partindo de um enfoque estritamente lógico-filosófico.

Um exemplo dessa atitude está, por exemplo, em um artigo de Renato Di Dio (1977), da Faculdade de Educação da Universidade de São Paulo, intitulado $O$ conceito de liberdade. Ao recordar que os conceitos de liberdade e determinismo são mutuamente exclusivos, o autor rejeita o segundo pela simples razão "de que levaria à completa dissolução de qualquer teoria, inclusive o próprio determinismo". A prova racional da liberdade estaria em que é um postulado necessário de qualquer sistema dotado de sentido. Se uma palavra tem valor (verdadeiro ou falso) seria porque foi escolhida livremente. E o único juiz dessa escolha seria o ser humano, com base em certos critérios. A crença de que todas as ações humanas são explicáveis por leis causais continuaria à espera de justificação. Não seria impensável negar que todo evento tem causa ou que a lei da causação universal seja uma pressuposição necessária do pensamento científico. Ao ver do autor, o cientista pode tentar descobrir leis causais e, em muitos casos, parece consegui-lo; mas suas inferências serão meramente estatísticas, logo, as leis causais estariam fundadas em nada mais que na probabilidade.

Como acredito que o professor Rocha Barros já tenha abordado o caráter probabilista das leis causais, gostaria de me ater a um ponto de argumentação de Di Dio, o que envolve a sua análise da emissão de uma palavra ao invés de outra que se desejaria emitir. O enfoque dado pelo autor na sua crítica ao determinismo, "eu teria somente a ilusão de ter escolhido a palavra certa, uma vez que a minha escolha se presume determinada", revela a freqüente defasagem que existe entre a análise lógico-filosófica e a decorrente do avanço científico, no caso da neurologia, que teria uma explicação algo determinista para a emissão da palavra errada, ou pelo menos da probabilidade dessa emissão. Tal defasagem tem sido responsável por muito desencontro e muita divergência. Piaget alertou para o fato de que os progressos na neurologia e na bioquímica (do cérebro) tornarão necessária uma completa revisão no campo da psicanálise (que será considerada uma teoria mística, segundo ele) e da psicologia.

$\mathrm{Na}$ verdade, a moderna psiquiatria, conservando o que há realmente de bom da teoria freudiana (tal como a moderna genética com relação ao darwinismo) 
cada vez mais faz uso dos avanços da fisiologia e da bioquímica do sistema nervoso para a explicação do comportamento. Exemplo disso está na análise transacional, criação do canadense Eric Berne com base nos experimentos de outro notável canadense, o neurologista Wilder Penfield, experimentos que levaram aos conceitos de córtex interpretativa, respostas experienciais e interpretativas. O livro de Berne, Games people play (1964), foi traduzido para o português com o título de Jogos da vida. A análise transacional tornou-se bem divulgada com o livro de Harris, I'm Ok-You're Ok (1973). O primeiro capítulo do livro intitula-se precisamente "Freud, Penfield \& Berne" e informa que a análise transacional não conflita com a psicanálise freudiana, antes a complementa e lhe dá substrato neurológico. Pois, "uma das razões para a crítica de que as ciências psicoterapêuticas não são científicas... é a de que não tem sido encontrada uma unidade básica para estudo e observação. É a mesma dificuldade encontrada pelos físicos antes da teoria molecular e pelos médicos antes da descoberta da bactéria". Berne propõe uma unidade básica científica para o relacionamento social, a transação. Se duas ou mais pessoas se encontram, cedo ou tarde, uma falará ou dará uma indicação de estar tomando conhecimento da presença dos outros. Isso é chamado o estímulo transacional. Outra pessoa então dirá ou fará algo que, de algum modo, está relacionado com o estímulo, e isso constituirá a resposta transacional.

É essa resposta transacional que está fundamentada nos achados de Penfield; ela inclui uma certa dose de determinismo. Como um transacionista encara o problema determinismo x liberdade? Harris ressalta a adesão de Freud e da maioria dos behaviouristas ao determinismo e as dificuldades advindas dessa atitude. Um dos locais onde o conflito determinismo versus liberdade é visto mais dramaticamente é nos tribunais. A posição judicial é que o homem é responsável; a determinística, subjacente em muitos testemunhos psiquiátricos, é a de que ele não é, em virtude de eventos passados. Para Harris, todavia, o determinismo na conduta humana difere do determinismo físico. Assim, não se pode negar a realidade de causa e efeito, por exemplo, quando uma bola de bilhar atinge muitas outras, que, por seu turno, atingem ainda outras, numa irrefutável seqüência em cadeia de causa e efeito. Mas, enquanto as bolas de bilhar não se tornam mais do que eram antes de se atingirem umas às outras, no caso humano as pessoas tornamse mais do que eram ao cabo de uma cadeia de eventos. A evidência de evolução - e de experiência pessoal - convence-nos de que o homem tornou-se, no caso, mais do que seus antecedentes. Assim, embora aceitando que o diferente comportamento de indivíduos numa circunstância possa encontrar uma resposta em algum lugar do passado (a base está em Penfield), o transacionista adiciona à análise o elemento evolução. O homem, pelo pensamento, é capaz de olhar para o futuro, ele é influenciado por um outro tipo de ordem causal, que Harteshorne (1954) chama "causação criativa". As causas do comportamento humano jazem não somente no seu passado, mas na capacidade do homem de contemplar o futuro, ou estimar probabilidades. A mente humana, segundo Trueblood (1963), opera largamente por referência a causas finais, o homem tem um presente constantemente dominado por um futuro não existente $e$, não obstante, potente; sua ação não é 
meramente o resultado de uma combinação mecânica de forças (como no caso das bolas de bilhar), a maior parte do pensamento diz respeito ao que poderia ser produzido, desde que certos passos pudessem ser tomados. Ortega y Gasset (1960) definiu o homem como um ser que consiste não tanto no que ele é, mas no que ele vai ser; afirmou ainda, dimensionando a liberdade, "eu sou eu e minhas circunstâncias". Assim, o transacionista vê o homem, sobretudo o adulto, como o lugar no qual existe a ação, reside a esperança e é possível a mudança.

A introdução de elementos tais como evolução, memória e pensamento, contemplação do futuro, a consideração do grau de organização e do nível de complexidade do agente tornariam inconsistente a irônica crítica que Bergson tentou fazer do determinismo. Ele fez várias incursões por domínios em que talvez não se achasse com segurança para falar, criando, por exemplo, conceitos tais como "evolução criadora", que, para o geneticista Goldschmidt (1953) inclui-se entre os “intangible word plays", que não-especialistas proferiram sobre a Evolução. Monod referiu-se a Bergson como possuidor de um estilo sedutor, uma dialética metafórica desprovida de lógica, mas não de poesia. Para Bergson (apud Durant, 1933), se o momento presente não contém uma escolha criativa e viva, e é total e mecanicamente o produto da matéria \& do movimento do momento anterior, então este último também foi o efeito mecânico do momento que o precedeu e, assim, para trás, até que se chegue à nebulosa primeva como a causa total de cada evento ulterior, de cada linha de peças de Shakespeare, de cada sofrimento de sua alma, de modo que as sombrias retóricas de Hamlet e Otelo, de Macbeth e Lear, em cada cláusula e em cada frase, já estavam escritas em seus distantes eons*.

Não me recordo se Bergson viveu suficientemente para assistir ao aparecimento da cibernética, a ciência do controle e da comunicação no animal e na máquina, fruto do trabalho conjunto de um físico e matemático (Wiener, 1948) e de um fisiologista (Rosenblueth), intrigados com as analogias entre os engenhos e o organismo. Se viveu, deveria ter estado alerta à importância do acontecimento. Wiener (1948) intitula o primeiro capítulo de seu livro precisamente "Newtonian and Bergsonian time" algo desfavorável ao filósofo francês, nele tratando amplamente da questão do automaton, dos gregos aos tempos modernos. Se tivesse estado atento à cibernética, que, atualmente permeia boa parte do raciocínio fisiológico, se, como preventivamente aconselha Davson (1951) tivesse aceito ao menos como analógica a comparação entre homeostase \& servo-mecanismos, entre a mente e os computadores, Bergson, talvez tivesse reformulado a sua crítica ao determinismo. Pois, num raciocínio analógico, pode-se bem reportar os atuais e complicadíssimos computadores aos minérios que constituíram as matérias primas de sua fabricação e, por que não?, à famosa nebulosa. Acontece, porém, que, tal como na evolução orgânica, os computadores evoluíram dependendo cada nova geração das precedentes e a ficção científica já se preocupa com essa evolução, que tem motivado até obras primas literárias e cinematográficas, como a Alphaville de Godard ou o 2001, uma odisséia no espaço de Kubric, calcada no livro de A. Clarke

* Do grego latinizado aeon, uma idade, um ciclo (Webster). 
Assim, os futuros computadores poderiam vir a ter um elemento de liberdade de vontade nas suas análises e respostas. Mas, é claro que essa livre vontade resultará da crescente complexidade de organização do computador que poderá gerar atitudes não-previstas por seus construtores. Fala-se já em doenças de computadores que têm a sua analogia em doenças mentais.

Poder-se-ia supor para os animais, em particular, e para o homem, em caso particularíssimo, uma evolução análoga à dos seus computadores neuro-sensoriais? No caso do homem, o computador já estaria tão desenvolvido e complexo que o levaria a exibir algo que vimos chamando liberdade de vontade, simplesmente porque a máquina cerebral, tal como os computadores do futuro, tem funcionamento e distúrbios que ainda não conseguimos entender satisfatoriamente? Creio que sim, com uma agravante. Os computadores que, no futuro, exibirem uma liberdade de vontade, terão tido gerações anteriores construídas pelo homem, ao passo que não houve obviamente participação alguma deste na construção da mente humana, cujos substrato morfológico e funcionamento no estágio evolutivo em que estão, o homem só pode vislumbrar através de experimentação e de homologias $\mathrm{e}$ analogias encontradas em animais inferiores.

Num notável artigo, Boring (1957) preocupou-se com a predeterminação do comportamento humano. Imaginando inclusive que o homem esteja robotizado pelo processo evolutivo, Boring fez considerações algo preocupantes sobre os seus status e destino. O cientista, diz Boring - porque o negócio da ciência é o estudo das causas e seus efeitos -, continua insistindo em que qualquer ação do homem pode ser referida às suas causas, que a explicação do seu comportamento está nos genes ancestrais, na sua experiência e em acidentes passados. O não-cientista tenderia a crer que o homem é livre a maior parte do tempo. De que lado está a verdade? É o homem perfeitamente livre para pensar (e agir) como quer ou são suas crenças (e ações) o reflexo do clima de fato e opinião que o envolve e das circunstâncias que pertencem ao século, ao país e à família em que vive?

O problema, segundo Boring, fica mais difícil quando se toma consciência de que a crença de ser o homem livre pode, ela própria, ser predeterminada. A crença na liberdade poderia ser a grande ilusão do homem. Poder-se-ia conceber uma sociedade de robôs falantes de tal maneira delineada, que eles continuassem a interagir de acordo com os princípios nos quais foram construídos, todos discorrendo sobre seus comportamentos com palavras que implicam cada um estar livre de escolher o que quiser e, cada um escolhendo livremente, torna-se assim responsável pela sua própria conduta - uma sociedade de robôs, na qual cada um se assegura de sua liberdade pela boa razão de que não é livre para negá-la.

Continuamos pensando - prossegue Boring - que a integridade de qualquer um de nós é tão grande que nossas seguranças e convicções são pelo menos parcialmente "autovalidantes", que o nosso sentido de certeza, embora possa flutuar, deve pelo menos tender para um ponto no sentido da verdade. Mas, e se a ilusão estiver realmente embutida dentro de nós? Se formos como robôs residentes de 
alguma utopia delineada por um psicólogo, de tal maneira estruturados para acreditar numa falsidade e jamais o saber, dos quais a verdade de seu determinismo básico está cuidadosamente escondida atrás de barreiras de racionalizações, às quais a segurança e a convicção estão firmemente atadas? A biologia não ofereceria proteção contra isso, pois há sempre a possibilidade de que a sobrevivência seja favorecida pela ilusão e o saber, se não for letal, pouco ajuda. Os países totalitários, com suas lavagens cerebrais e suas forçadas auto-acusações, mostraram que a integridade do homem - a cidadela de sua liberdade - pode ser invadida, a opinião do homem, a sua fé, a sua consciência podem ser escravizadas. Assim, segundo Boring, o sentido de liberdade poderia estar se tornando a grande ilusão do homem.

No mesmo sentido, Boring reporta-se a uma divergência tida com seu colega de universidade (Harvard), o psicólogo W. McDougall, que acreditava na liberdade da mente humana ou, ao menos, num resíduo dela. Recorda que, para o psicólogo determinista, essa crença é cientificamente imoral. J.B. Watson, o fundador do behaviourismo, revendo a edição da época do tratado de $\mathrm{McDougall}$, intitulou ironicamente sua resenha crítica de "O Prof. McDougall retorna à religião". Boring se preocupava com McDougall e determinismo e, então, numa dessas raras ocasiões (surgida em um colóquio com o colega) em que o argumento dá esclarecimento e não, meramente, endurece preconceitos, Boring atinou com a diferença entre ele, determinista, e McDougall, voluntarista. A liberdade de McDougall era a variância de Boring. McDougall esperava que a variância seria sempre encontrada na especificação das leis do comportamento e, aí, a liberdade poderia ainda persistir; Boring acreditava que a ciência continuaria pressionando a variância, tendo o zero como limite. Assim, a liberdade, quando se crê que ela está operando, sempre residiria numa área de ignorância: se houver uma lei conhecida, não se tem liberdade.

Eu poderia continuar exemplificando e analisando, mas, então, correria o risco de me afundar no "atolladero" de que me falou o Dr. Roche, estando, talvez, já com os pés nas bordas do mesmo. Assim, seria bom finalmente entrar na discussão da possibilidade biológica de haver livre vontade. Descartes considerava os animais como automata, talvez, como assinalou Wiener, para não questionar a atitude cristã ortodoxa de que eles não têm alma para ser salva ou danada. Mas não se preocupou em saber como esses automata vivos funcionam. Em compensação, especulou sobre modo de acoplamento da alma e do corpo, sugerindo que o seu sítio estaria na glândula pineal do homem. $\mathrm{O}$ atual avanço da fisiologia neuro-sensorial e da ciência do comportamento autorizaria quase a aceitar que, em determinado grupo de animais, até em certos dos chamados inferiores (como os cefalópodos, os insetos sociais), o computador - sistema neuro-sensorial - estaria já de tal forma desenvolvido que as respostas neles observáveis incluiriam um elemento comparável à vontade livre do homem. Assim, esse elemento surgiria em um determinado estágio de complexação do computador neuro-sensorial e apenas é mais aferível, no caso do homem, porque nele existe a possibilidade da comunicação oral e escrita, a qual nos permite dizer que ele emerge evoluído de qualquer evento novo e pode contemplar o futuro em termos de experiência presente e passada. 
Recentes achados da neurofisiologia - no campo das áreas nervosas associadas - e da genética humana - no sentido de vincular anormalidades físicas e mentais a alterações fisiológicas ou gênicas - tenderiam a pressionar a variância de que fala Boring, em detrimento da liberdade da vontade.

No caso neurofisiológico, vou me limitar a três exemplos. O primeiro diz respeito ao córtex (ou área) orbitofrontal e personalidade. Em 1936, com base nos notáveis experimentos do mesmo ano de Fulton \& Jacobson (Crawford et al., 1948), Egas Moniz demonstrou a possibilidade de alterar o comportamento humano anormal ou normal, mediante a destruição da projeção para regiões préfrontais a partir do tálamo. Assim, por um ataque cirúrgico (leucotomia), psicóticos tornam-se tranqüilos, até apáticos. Normais afetados por dor intratável, após essa chamada leucotomia frontal, obtêm um alívio considerável e curioso: não que a dor física tenha desaparecido, apenas não ligam mais para ela, não ficam mais angustiados e temerosos como antes. Assim, aparentemente, é a atitude para com a dor que está alterada. A personalidade de tais normais leucotomizados muda claramente. Esmorecem o pensamento e a atividade, os operados carecem completamente de expressão ou disposição emocionais, têm um interesse extremamente reduzido e falta-lhes drive (élan). O comportamento torna-se menos responsável e agem com falta de tato. A memória e a experiência passada parecem inalteradas, mas a capacidade criativa e a visualização de um problema ficam seria ou totalmente comprometidas.

A leucotomia atinge elementos do chamado sistema límbico, o que nos leva ao segundo exemplo. Esse sistema inclui o chamado córtex límbico e áreas subjacentes. Entre essas áreas estão centros hipotalâmicos, o hipocampo e a amígdala. Segundo Fulton, a leucotomia frontal interromperia o feixe de fibras da dor do hipotálamo para duas estruturas límbicas, a insula e o giro orbital. Os centros hipotalâmicos límbicos incluem o de recompensa e o de punição, tendo sido experimentalmente demonstrado que a aprendizagem está intimamente ligada à estimulação desses dois centros. Estímulos sensoriais não sustentam a resposta cortical se não excitarem concomitantemente os centros límbicos. A amigdala relaciona-se primariamente com a associação de estímulos olfativos a estímulos de outras áreas cerebrais e, sob muitos aspectos, complementa a ação dos centros hipotalâmicos. A estimulação de certos de seus núcleos induz um padrão de raiva como o de Hess, reações de fuga, ativa a sexualidade e atos pertinentes. Ação complementar ou auxiliar tem também o hipocampo, envolvido na memória, que se caracteriza, além disso, por antagonizar a formação reticular ascendente, no fenômeno da atenção. Ao passo que essa formação orienta a atenção para áreas especificas do intelecto, a estimulação do hipocampo induz, numa conversa, a perda de contato com o interlocutor. Além disso, dessa estimulação podem resultar alucinações incontroláveis, ainda que a pessoa se dê conta de seu caráter irreal.

Toda essa atividade límbica, aqui esboçada fragmentáriamente e de forma muito resumida, confere à região em questão foros de um computador encarregado de processar informação sensorial (tal como o cerebelo processa informação 
para equilíbrio, postura e movimentos), para integrá-la de algum modo no todo da vida pensante do organismo, dar-lhe significado com relação à experiência vivida $\mathrm{e}$, talvez, colori-la com um tom emocional.

A referência à experiência passada conduz-me ao terceiro exemplo que se prende aos experimentos de Penfield (1955), a que se fez alusão anteriormente a propósito da análise transacional. Penfield partiu do fato de que epiléticos sempre têm a mesma aura (= a re-encenação mental de uma experiência passada) no início do ataque, seguindo-se ou não a fase convulsiva. Numa jovem paciente ele conseguiu, durante uma cirurgia, evocar essa mesma aura mediante estimulação elétrica. Em pacientes não epiléticos, passeando com o estimulador numa região do lobo temporal que descreveu como córtex interpretativa, Penfield observou dois tipos de resposta. No primeiro, o paciente, ao acaso, ouvia ou via um episódio ou fato de que tivesse participado no passado. Como se um toca-fitas ou um trecho de um filme sonoro tivessem sido postos em ação. Penfield denominou esse tipo de resposta (ou alucinação) "experiencial". No segundo tipo, de acordo com trecho da área atingida, ocorria uma má-interpretação do significado da experiência presente, objetos pareciam maiores ou menores que o normal, a própria voz do interlocutor ficava extremamente alta ou baixa ou o paciente experimentava um sentimento de medo ou confiança, sem óbvia razão para tal. Penfield denominou tal resposta (ou ilusão) "interpretativa”. Admitindo ter apenas aflorado o mecanismo da memória no caso das respostas experienciais, Penfield sugeriu que a experiência passada parece ficar "gravada" em "fitas" neurônicas, que normalmente a gente "toca" à vista de experiência presente (em processo de "gravação" também). Recordar seria retirar do arquivo dessas "fitas de memória", aquela fita correspondente à circunstância. Na resposta do tipo interpretativo, admite-se que a área estimulada seja associada com áreas límbicas.

Todos esses resultados sugerem que um dado comportamento ou atitude e, talvez, mesmo uma opção ou escolha contenham muito pouco do resíduo de livre vontade que McDougall aceitava, o qual seria resistente à pressão do avanço do conhecimento sobre a variância de Boring. Poderiam, ainda, ser acrescentados mais subsídios para reforçar essa admissão. Assim, um morfinômano é incapaz de se libertar do vício porque a morfina intensificaria a síntese e a utilização de adrenalina nas vizinhanças do centro da recompensa hipotalâmico, causando uma permanente euforia.

Em indivíduos nos quais ocorreu secção do corpo caloso, que contém fibras comissurais que fazem a conexão entre os dois hemisférios cerebrais, Sperry (1968) e colaboradores observaram impressionantes modificações do comportamento. Um desses pacientes com cérebro dividido descobriu-se a si mesmo agredindo a esposa com a mão esquerda (controlada pelo hemisfério cerebral direito), enquanto tentava impedir isso com a mão direita (controlada pelo hemisfério cerebral esquerdo). O hemisfério esquerdo é mais do que a sede da fala e da linguagem, é o lugar de origem da capacidade analítica da mente; no hemisfério direito residem os talentos artísticos, mais intuitivos, do indivíduo. 
Por outro lado, o indivíduo pode estar genotipicamente condicionado para exibir um peculiar comportamento. Se o cromossomo 21 ocorrer em dose tripla em vez de dupla, ele exibirá a síndrome de Down (Lejeune et al., 1959); se lhe faltar um cromossomo X, será portador da síndrome de Turner - disgênese gonadal (Ford et al., 1959); se for homem e portador de dois cromossomos Y (Ford \& Strong, 1959) estará geneticamente predeterminado a ser agressivo. Tais indivíduos XYY são freqüentemente encontrados em instituições penais e, tanto mais, se sua vida pregressa tiver decorrido em ambiente favorável à manifestação desse comportamento geneticamente condicionado.

De novo, esses resultados indicariam fortemente uma predeterminação do comportamento humano, dificultando a aceitação de uma liberdade de vontade, nos moldes em que ela é tradicionalmente aceita por muitos estudiosos. Como, então, entender a decisão do homem diante de um fato e uma situação, de que deve sair ou solucionar, para, enfim, sobreviver? Do que foi dito anteriormente, ficaria patente que essa decisão será o produto da atividade de complexos mecanismos do organismo (dentre os quais, ia me esquecendo de dizer, ressalta o balanço endócrino) mais o meio e suas solicitações. Distúrbios nesses mecanismos e no meio podem prejudicar grandemente essa decisão, que surgirá errada em termos de sobrevivência e de prejuízos causados à sociedade. De tal sorte que à conhecida frase "Dize-me com quem andas e dir-te-ei quem és" poder-se-ia acrescentar, intercalando, "dize-me com quem andas, o teu genótipo e a tua condição fisiológica geral e dir-te-ei quem és".

Estaria eu, com isso, negando peremptoriamente a liberdade da vontade? Não, pelo menos até que o avanço científico pressione definitivamente para zero a variância de que falou Boring. Mas ele próprio parece ter colocado esse zero como um limite inatingível. No fundo, o mistério da liberdade da vontade perdurará, como tantos outros mistérios científicos, por um tempo indefinido. Talvez, como disse já anteriormente, essa liberdade da vontade permaneça como resíduo insolúvel na análise físico-química que se vem fazendo do comportamento animal. Com base em Needham (1942), que afirmou achar estéril a disputa em torno da redutibilidade ou irredutibilidade dos fatos biológicos a fatos físico-químicos puros, porque se trata apenas de níveis diferentes de organização, poder-se-ia dizer que o computador de cujo funcionamento resulta a mente humana capaz de optar e de opinar, seja de um tal elevado nível de organização que, por muito tempo ainda, desafiará a análise científica.

De que valeria, porém, a ciência informar à justiça, sobre o grau de responsabilidade de quem comete um delito? Acredito que somente para a dosagem da pena e a tomada de providências no sentido de recuperação e eventual re-integração na sociedade e, quando isso não for possível, uma reclusão, em que os direitos fundamentais do homem sejam respeitados e as suas necessidades biológicas e médicas atendidas. Assim, haverá que ouvir o etólogo, o psicólogo, o sociólogo e o psiquiatra para a consecução dessa finalidade. É isso precisamente que se está tentando fazer em tipos de reuniões como estas. 
Referências bibliográficas

BERNE, E. Games people play. New York, Grove Press, 1964.

BORING, E.G. When is human behaviour predetermined? A Richard M. Elliott Lecture in Psychology. Scientific Monthly, v. 84, p. 189-196, 1957.

CRAWFORD, M.P.; FULTON, J.F.; JACOBSEN, C.F. \& WOLF, J.B. Frontal lobe ablation in chimpanzee: a resumé of "Becky" and "Lucy". ARNMD n. 27, p. 3-58, 1948.

DAVSON, H. \& EGGLETON, E. The principles of human physiology. London, Churchill, 1951.

DI DIO, R. Conceito de liberdade. Suplemento Cultura, O Estado de S. Paulo, ano 1, n. 3, p. 5-6, 1976.

DURANT, W. The story of philosophy. New York, Simon \& Schuster, 1933.

FORD, C.E.; JONES, K.W.; POLANI, P.E.; ALMEIDA, J.C. \& BRIGGS, J.H. A sex-chromosome anomaly in a case of gonadal dysgenesis (Turner's syndrome). Lancet, v. 1, p. 711-713, 1959.

GOLDSCHMIDT, R. An introduction to a popularized symposium on evolution. Scientific Monthly, v. 77, p. 182-189, 1953.

HARRIS, T.A. I'm Ok- You're Ok. New York, Avon Books. Harpers \& Row, 1973.

HARTERSHORNE, C. Causal necessities, an alternative to Hume. The Philosophical Review, v. 63, p. 479-499, 1954.

JACOBS, P.A. \& STRONG, J.A. A case of human intersexuality having a possible XXY sex-determining mechanism. Nature, v. 183, p. 302-303, 1959.

LEJEUNE, J.; GAUTHIER, M. \& TURPIN, R.S. Étude des chromosomes somatiques de neuf enfants mongoliens. C.R.Acad. Sci., Paris, n. 248, p. 1721-722, 1959.

MONIZ, E. Tentatives opératoires dans le traitment des certaines psychoses. Paris, Masson, 1936.

NEEDHAM, J. Morphogenesis and biochemistry. Cambridge, Cambridge University Press, 1942.

ORTEGA Y GASSET, J. What is philosophy? New York, Norton, 1960.

PENFIELD, W. The interpretative cortex. Science, n. 129, p. 1719-1725, 1959.

SPERRY, R.W. Mental activity following surgical disconnection of cerebral hemisphere. The Harvey Lectures. Serie 62, p. 293-323, 1968.

TRUEBLOOD, E. General philosophy. New York, Harper, 1963.

WIENER, N. Cybernetics (or the control and communication in the animal and the machine). New York, The Technological Press Wiley \& Sons, 1948. 
RESUMO - A questão determinismo versus liberdade da vontade foi enfocada em termos de conhecimentos de neurociências, evolução, genética e informática, com vistas à difícil tarefa de contribuir para a caracterização da responsabilidade do homem face a seus atos e, assim, oferecer subsídios para a reforma do Código Penal Brasileiro.

ABSTRACT - The question determinism versus free will was focussed in terms of the knowledge of neurosciences, evolution, genetics and information theory, aiming at the hard task of attempting to contribute to the caracterization of man's responsability towards his acts and, thus, offer elements for the reformation of the Brazilian Penal Code.

Erasmo G. Mendes é titular aposentado de Fisiologia Animal, Professor Emérito do Instituto de Biociências da USP e membro da mesa editorial de ESTUDOS AVANÇADOS. 